\title{
2017 National Dental Nursing Conference
}

Conference was held on 17 and 18 November 2017 by the British Association of Dental Nurses (BADN) at the Milton Keynes Hilton, and was opened by Keynote Speaker Postgraduate Dental Dean John Darby at the Opening Ceremony where incoming President Hazel Coey accepted the chain of office from outgoing President Jane Dalgarno.

Former Chair Debbie Reed also presented Chief Exec Pam Swain with a bouquet of flowers to mark her 25 years of working for the Association.

The afternoon programme began with TePe's Elaine Tilling on 'Healthy Habit Formation, followed by Dentaid's Jill Harding on 'Volunteering with Dentaid' and finished up with Matthew Hill, Director of Strategy at the General Dental Council (GDC), updating delegates on what's happening at the GDC. This was followed by a fairly lively Q\&A session.

Saturday kicked off with a very interesting presentation on 'Dental Nursing in Oman' by Omani dental nurse Yassmen al-Lawaiti. Not only did Yassmen outline the training and work environment of dental nurses (or assistants, as they are still called) there, she also told us about Oman - whose National Day it was - with maps, badges and samples of halva.

Yassmen was followed by Past President Angie McBain-Heilmann MBE and Adrian Buckingham, MD of Dental Hygienics and Decontamination Ltd, on 'What the Butler Saw!' - a cautionary tale of decontamination gone wrong, which caused several delegates to check up on their own practices as soon as they returned to work!

Health Education England's Katy Kerr was next on 'Dementia Friendly Dentistry' and the lecture programme finished with the second GDC speaker of the Conference, Head of Standards Janet Collins on 'Enhanced CPD - What It Means for Dental Nurses.'

At the Closing Ceremony, President Hazel presented Maureen Stone with the BADN 2017 Award for Outstanding Services to Dental Nursing Professional Practice.

BADN no longer hold a black tie Presidential Dinner, but the informal dinner on Friday night was certainly lively. Presidents Hazel Coey and Jane Dalgarno presented Pam Swain with a bottle of champagne and glasses from the Executive Committee to celebrate her Silver Anniversary with the Association.

Outside the Conference room, Isopharm were demonstrating products and answering questions, and the University of Kent was encouraging delegates to consider furthering their dental education.

BADN would like to thank all the speakers: sponsors Isopharm, Oral Health Foundation, Purple Media, Robinson Healthcare, Splat, and the University of Kent, and all who supported BADN and the National Dental Nursing Conference by attending. The 2018 National Dental Nursing Conference will be held in November at the Blackpool Hilton.
New gramts available for alental hygienists and

\section{therapists}

The British Society of Dental Hygiene and Therapy (BSDHT) is dedicated to helping its members provide the care their patients need.

In line with this ethos, it is delighted to be collaborating with the Wrigley Company Foundation to offer members the opportunity to apply for community service grants.

These grants are intended to support oral health promotion and projects within local communities and provide successful applicants with up to $£ 1,500$ to continue their great work.

To apply, members need only complete a form about their proposed project and demonstrate what the money would be used for.

This is yet another way the BSDHT is supporting its members and enabling them deliver the very best care for all of their patients.

To find out more about membership, or to request a form for a BSDHT/Wrigley Company Foundation grant, visit the website or contact the team today.

For more information about the BSDHT, visit www.bsdht.org.uk, call 01788 575050 or email enquiries@bsdht.org.

\section{9th DCP}

\section{Symposium to be held in Cardiff}

The Dental Postgraduate Section of the Wales Deanery in collaboration with The Royal College of Surgeons Edinburgh will be holding its 9th DCP Symposium on Friday 18 May 2018 at the Marriott Hotel, Mill Lane, Cardiff.

For further information please contact Liddingtonke@cf.ac.uk or Hayeskj@ cardiff.ac.uk 